\title{
A Study of Solid-Free Drilling Fluid for Tight Gas Reservoirs
}

\author{
Wenwu Zheng1, Fu Liu', Jing Han1, Binbin He1, Xintong Li2 ${ }^{*}$, Qichao Cao² \\ ${ }^{1}$ Sinopec North China Petroleum Engineering Co, Ltd., Zhengzhou, China \\ ${ }^{2}$ Yangtze University, Jingzhou, China \\ Email: ${ }^{7} 791153254 @ q q . c o m$
}

How to cite this paper: Zheng, W.W., Liu, F., Han, J., He, B.B., Li, X.T. and Cao, Q.C. (2021) A Study of Solid-Free Drilling Fluid for Tight Gas Reservoirs. Open Journal of Yangtze Gas and Oil, 6, 13-23. https://doi.org/10.4236/ojogas.2021.61002

Received: November 2, 2020

Accepted: January 25, 2021

Published: January 28, 2021

Copyright $\odot 2021$ by author(s) and Scientific Research Publishing Inc. This work is licensed under the Creative Commons Attribution International License (CC BY 4.0).

http://creativecommons.org/licenses/by/4.0/

\begin{abstract}
This project is explaining a laboratory development of a solid free drilling fluid formula that could be potentially used in tight gas reservoirs. The configuration of the weak gel fluid WGL-1, which is resistant to high temperature and high salt, was tested, and concluded that its gelling properties, salt and temperature resistance, and environmental protection were all in line with industry requirements. The final drilling fluid formula was developed as: water $+(0.3 \%-$ $0.5 \%) \mathrm{NaOH}+5 \% \mathrm{KCl}+2 \%$ WGL-1 + 5\% NaCl $+(1.0 \%-2.0 \%)$ HBFR Anti-high temperature fluid loss agent $+2 \%$ Polyol $+(1.5 \%-2.0 \%)$ SDL-1 Lubricant $+0.4 \% \mathrm{~A} 4 \mathrm{O} 1$. The performance of the liquid was tested for temperature resistance, inhibition, gas formation protection effect, plugging performance, and static settlement stability. It was concluded that the temperature resistance performance is satisfied at $150^{\circ} \mathrm{C}$, and the cuttings recovery rate is as high as $96.78 \%$. It has good performance in inhibiting water dispersion and swelling of cuttings. The permeability recovery value reaches $88.9 \%$, which meets the requirements of gas formation protection. The SSSI value shows that its settlement stability is good; under high temperature and high pressure, its sealing performance is good. This drilling fluid system has achieved the expected results and laid a foundation for further promoting the development of solid-free drilling fluid systems. The future development direction of solid-free drilling fluids is pointed out, to the improvement of properties to be applied in high temperature environment and have high salt resistance capacity.
\end{abstract}

\section{Keywords}

Tight Gas Reservoir, Solid-Free Drilling Fluid, Temperature Resistance, Environmental Protection, Weak Gel

\section{Introduction}

Tight gas has now become a very important unconventional natural gas re- 
source. It not only occupies a very important position in China but is also a very important strategic energy reserve in the global scale. However, with the deepening of the exploration and development of oil and gas fields, the construction of deep exploratory wells and drilling has gradually increased, and the requirements for increasing the ROP, shortening the drilling cycle, and protecting the reservoir have accordingly increased [1] [2] [3].

The conventional water-based drilling fluids contain bentonite slurry as a base compound.

The solid content is relatively high, and sub-micron particles occupy a large proportion of the fluid. This leads to low inhibition of the system, but also viscosity and shear force increase. Because of the stickiness of clay particles, it is easy to stick to the surface of the drill bit, which makes keen of increasing the rate of penetration [1] [2] [3].

Oil-based drilling fluid has high economic costs for its preparation and maintenance and is not friendly to the environment. The economic costs of its harmless treatment are high. The discharge of drilling fluid is also an important issue to be considered. Therefore, the system promotion and application have received greater constraints. In relatively special geology containing salt-gypsum layers, both water-based and oil-based drilling fluids are not suitable for application. When salt intrusion occurs, borehole imbalance is likely to occur, which increases construction risks. Therefore, the study of solid-free drilling fluid is needed to meet the requirements [1] [2] [3].

The purpose of this article is to receiving a new formula of solid-phase weak gel drilling fluid by laboratory activities. This project is intended to contribute to the development of solid-free weak gel drilling fluids at high temperature and high pressure and lay a foundation for further promoting the development of solid-free drilling fluid systems [1] [2] [3]. The test results are shown as well: resistance to high temperature and pressure, resistance to flow, inhibition, gas formation protection and other properties.

\section{WGL-1 Synthesis of Weak Gel}

\subsection{Determination of Synthetic Materials}

Weak gel thickeners are generally made of biodegradable natural macromolecules and other materials. Among them, the high temperature resistance starch is very important component, but the domestic modified starches are developing slowly. Not only are there a few types, but their temperature resistance cannot meet the needs of high temperature. When they are biodegraded by bacteria their properties deteriorate. The fluid becomes foamy and smelly [4] [5] [6]. In the actual drilling operation, even if the application temperature of modified starch can reach up to $130^{\circ} \mathrm{C}$, the stability of starch begins to show a downward trend after reaching $100^{\circ} \mathrm{C}$. Therefore, to meet the current market needs there is a need for more in-depth research and development [7] [8]. 


\subsection{Determination of Synthesis Conditions}

Under normal circumstances, the experimental conditions that affect the free radical polymerization reaction include:

- reaction time and temperature,

- $-\mathrm{pH}$,

- monomer concentration.

These synthesis conditions more or less affect the high temperature and salt resistance properties of the synthesized WGL-1. Only the synthetic WGL-1 forms a special structure in the drilling fluid and has high viscosity value at low shear rate or at rest. It has a high viscosity value at a low shear rate or at rest, which plays a role in static suspension cuttings. The experimental conditions in this article are determined based on repeated experiments such as previous empirical theories, experimental reports, and patent results.

\subsection{Instrument and Development}

The main instruments and equipment used in the laboratory synthesis experiment are shown in Figure 1.

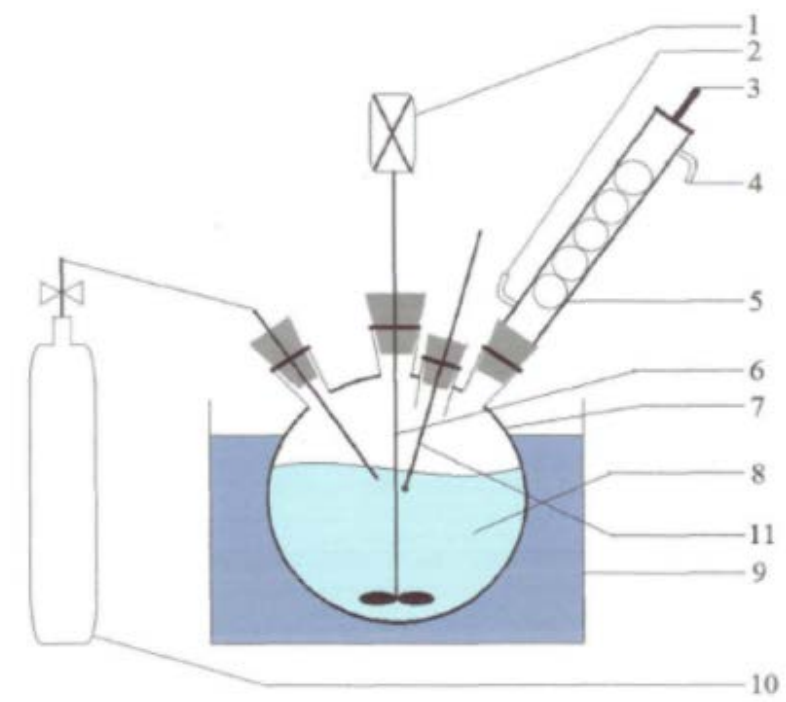

1. Electric stirrer 2. Condensate water inlet 3. Condensate outlet (open to the atmosphere) 4. Condensate water outlet 5. Spherical condenser 6. Stirring paddle 7. Round bottom four-neck flask 8. Aqueous solution 9. Constant temperature water bath 10. Nitrogen bottle 11. Thermometer

Figure 1. Schematic diagram of synthetic experimental device.

The first step of the production is to mix about $7.5 \mathrm{~g}$ of surfactant with 142.5 $\mathrm{mL}$ of water as a solvent to obtain an aqueous solution with $7 \%$ surfactant content. Put it into a round-bottomed four-neck flask and pre-heat it in a constant temperature water bath at $80^{\circ} \mathrm{C}-90^{\circ} \mathrm{C}$. In the process of keeping stirring, add $100 \mathrm{~g}$ of high temperature resistant modified starch FSL. After about $6-8 \mathrm{~h}$, the product is dried and crushed at $105^{\circ} \mathrm{C}$. The resultant content after 200 mesh screening is combined with cellulose inorganic acid ester. The oxidizer 923 is 
compounded to obtain the final desired product WGL-1.

\section{Performance Evaluation}

\subsection{Gelling Performance Evaluation}

Add $98 \mathrm{~mL}$ of distilled water into a $200 \mathrm{~mL}$ beaker, use a stirrer to stir at 3000 $\mathrm{r} / \mathrm{min}$, add $2.0 \mathrm{~g}$ WGL-1 while stirring, continue stirring for 10 minutes after adding stirring, and after standing for a period of time, observe WGL-1 gel time and the state after gelation. In order to highlight the gel forming properties of WGL-1, compare it with the commonly used tackifiers HV-CMC, HEC, PF-PRD and HF-1. The results are shown in Table 1.

Table 1. Tackifier gel time.

\begin{tabular}{rrrrr}
\hline Tackifier Water/g Tackifier/g & $\begin{array}{r}\text { Name of gel } \\
\text { forming agent }\end{array}$ \\
\hline WGL-1 & 98 & 2 & Nol forming agent/g Transaction time/min \\
HV-CMC & 98 & 2 Potassium dichromate & 0 & 5.5 \\
HEC & 98 & 2 Potassium dichromate & 0.5 & 9 \\
PF-PRD & 98 & 2 Potassium dichromate & 0 & 11 \\
HF-1 & 98 & 2 Potassium dichromate & 0.5 & 7 \\
\hline
\end{tabular}

It can be seen from Table 1 that WGL-1 has good gel forming performance, relatively short gel forming time, and does not need to add any gel forming agent.

\subsection{Evaluation of Salt and Temperature Resistance}

Take $450 \mathrm{ml}$ of distilled water, then add $50 \mathrm{~g} \mathrm{NaCl}$ to it, mix and dissolve it thoroughly to form a $10 \%$ salt solution. Place it in a high stirring cup, then put $1.2 \mathrm{~g}$ $\mathrm{Na}_{2} \mathrm{CO}_{3}$ into the cup, and set the speed to $10,000 \mathrm{r} / \mathrm{min}$. While stirring, put in $10.0 \mathrm{~g}$ WGL-1, after stirring for 20 minutes, put it at room temperature for airtight hydration for 4 hours, then stir at high speed for 5 minutes. Then put it in a roller oven, and keep it at a constant temperature at $160^{\circ} \mathrm{C}$. Roll it, take it out for $16 \mathrm{~h}$ and cool it until it reaches the temperature and room temperature. Then stir it at high speed for $5 \mathrm{~min}$, and test the product on a six-speed rotary viscometer according to GB/T 16783.1-2006 regulations to determine its viscosity, dynamic shear and static shear. The product was measured under the condition of $0.3 \mathrm{r} / \mathrm{min}$ with a DV- II viscometer to obtain the low shear rate viscosity of the product. While conducting the test, in order to better understand the advantages and disadvantages of its performance, for this reason, other tackifiers were subjected to the same experiment as a control group. The results are shown in Table 2.

It can be seen from Table 2 that WGL-1 not only has good salt resistance and temperature resistance, but also has good viscosity under low shear rate conditions. It is dozens of conventional tackifiers HV-CMC and HEC. Its sand-carrying 
ability is very strong, and it can meet the requirements of drilling fluid in complex engineering. WGL-1 is superior to PF-PRD and HF-1 in salt and temperature resistance, and its low shear rate viscosity is a multiple of them.

Table 2. Evaluation of anti-high temperature and high salt performance of tackifier.

\begin{tabular}{rrrrrrr}
\hline Tackifier & AV/mPa.s & PV/mPa.s & YP/Pa & \multicolumn{2}{c}{ Static force/Pa } & $\begin{array}{r}\text { Low shear rate } \\
\text { viscosity/mPa.s }\end{array}$ \\
\hline WGL-1 & 38.5 & 19.9 & 18.5 & 6.3 & 7.6 & 85,025 \\
HV-CMC & 11.4 & 6.8 & 4.9 & 1.3 & 1.8 & 1858 \\
HEC & 20.2 & 11.8 & 8.8 & 2.3 & 2.8 & 3411 \\
PF-PRD & 31.7 & 17.9 & 13.9 & 2.8 & 5.7 & 18,685 \\
HF-1 & 28.8 & 20.8 & 8.4 & 2.4 & 6.4 & 4128 \\
\hline
\end{tabular}

\subsection{Environmental Performance Evaluation}

Two important environmental protection indicators biodegradability and acute biological toxicity are used as references for its environmental performance [9]. The biodegradability evaluation is based on $\mathrm{BOD}_{5} / \mathrm{COD}$ (5 Day biochemical oxygen demand to Chemical oxygen demand). The WGL-1 values of $\mathrm{BOD}_{5}$ and COD are calculated separately, and then the ratio is obtained. Acute biological toxicity is determined in accordance with GB/T15441-1995 "Water Quality, Acute Toxicity Determination and Photoluminescent Bacteria Law" as the standard to determine the acute biological toxicity WGL-1 of $\mathrm{EC}_{50}$. The experimental results are shown in Table 3.

Table 3. Comparison of environmental performance.

\begin{tabular}{rrrrr}
\hline Tackifier & $\mathrm{BOD}_{5} / \mathrm{mg}^{-\mathrm{L}^{-1}}$ & $\mathrm{COD} / \mathrm{mg} \cdot \mathrm{L}^{-1}$ & $\mathrm{BOD}_{5} / \mathrm{COD}$ & $\mathrm{EC}_{50} / \mathrm{mg} \cdot \mathrm{L}^{-1}$ \\
\hline WGL-1 & 95.38 & 371 & 0.257 & 152,899 \\
HV-CMC & 18.11 & 417 & 0.043 & 54,857 \\
HEC & 52.14 & 601 & 0.087 & 36,857 \\
PF-PRD & 62.99 & 471 & 0.134 & 87,546 \\
HF-1 & 148.79 & 2189 & 0.067 & 23,548 \\
\hline
\end{tabular}

Refer to the relevant classification standards [10] [11] from Table 3, it can be found that the environmental performance of WGL-1 is not only biodegradable than other tackifiers, but also non-toxic, meeting the requirements of environmental protection for drilling.

\section{Drilling Fluid Formula and Performance}

\subsection{Formula}

The final formula is determined as:

Water $+(0.3 \% \sim 0.5 \%) \mathrm{NaOH}+5 \% \mathrm{KCl}+2 \%$ WGL-1 $+5 \% \mathrm{NaCl}+(1.0 \% \sim$ $2.0 \%)$ HBFR Anti-high temperature fluid loss agent $+2 \%$ Polyol $+(1.5 \% \sim 2.0 \%)$ 
SDL-1 Lubricant + 0.4\% A4O1.

\subsection{Evaluation of Temperature Resistance}

Whether the influence of temperature is reversible or not is the main content to investigate the temperature resistance of drilling fluid [12]. The performance before and after hot rolling of the test formula is shown in Table 4. The solid-phase weak gel drilling fluid prepared by WGL-1 was heated at different temperatures for 16 hours, and then the structural and morphological changes were observed by environmental scanning electron microscope. The results are shown in Figure 2.

Table 4. Hot roll front and back performance.

\begin{tabular}{rrrrrr}
\hline Experimental conditions & $\mathrm{PV} / \mathrm{mPa} \cdot \mathrm{s}$ & $\mathrm{YP} / \mathrm{Pa}$ & $\mathrm{Gel} / \mathrm{Pa} / \mathrm{Pa}$ & $\mathrm{FL}_{\mathrm{API}} / \mathrm{mL}$ & $\mathrm{FL}_{\mathrm{HTHP}} / \mathrm{mL}$ \\
\hline Room temperature & 30 & 27.3 & $4.8 / 6.9$ & 2.4 & 15.7 \\
$150^{\circ} \mathrm{C}, 16 \mathrm{~h}$ & 28 & 17.2 & $3.8 / 4.5$ & 3.5 & 18.9 \\
$160^{\circ} \mathrm{C}, 16 \mathrm{~h}$ & 22 & 11.2 & $1.9 / 2.9$ & 5.1 & 20.9 \\
\hline
\end{tabular}

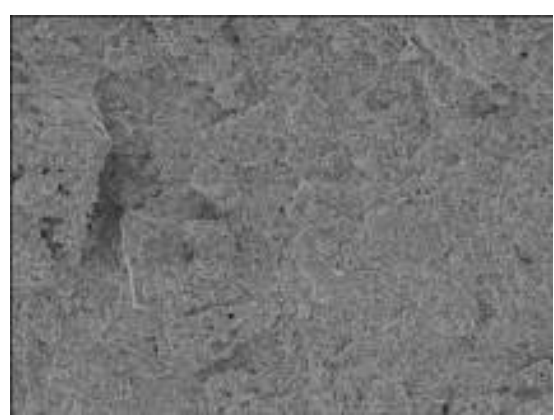

(a)

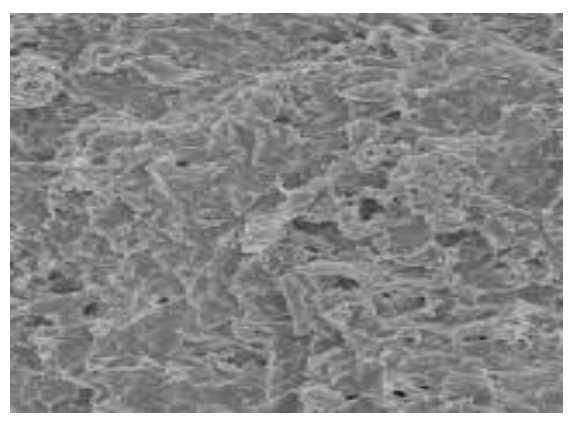

(b)

Figure 2. Micro-topography after hot rolling. (a) $50 \mu \mathrm{m}$ (After aging at $90^{\circ} \mathrm{C}$ ); (b) $10 \mu \mathrm{m}$ (After aging at $160^{\circ} \mathrm{C}$ ).

Figure 2 presents the microscopic morphology. Under the different temperature aging, especially after high temperature aging, the network space structure of the solid-phase weak gel drilling fluid is basically maintained well. The rheological property of the solid-free weak gel drilling fluid is proved to be excellent microscopically. The excellent variable performance has been proved microscopically. It can be seen from Table 4 and Figure 2 that the drilling fluid has stable performance at high temperatures, not only has good rheological properties, but also has the advantage of low fluid loss, which meets the original purpose of the research.

\subsection{Suppression Performance Evaluation}

During the drilling process, if the clay minerals are hydrated and dispersed, problems such as poor drilling fluid purification, filtration loss and rheological parameters are difficult to control during the drilling [13]. In this experiment, a core immersion experiment was used to evaluate the coating inhibition perfor- 
mance of the treatment agent. The easily dispersed shale was used as the experimental material [14] [15] [16]. The recovery rates of distilled water (series 1), commonly used weak gel drilling fluids (series 2) and prepared drilling fluids (series 3$)\left(150^{\circ} \mathrm{C}, 16 \mathrm{~h}\right)$ are $21.1 \%, 83.8 \%$ and $96.78 \%$, respectively. The cuttings in the recovery rate of the configured drilling fluid were much higher than that of the commonly used weak gel drilling fluid as shown in Figure 3.

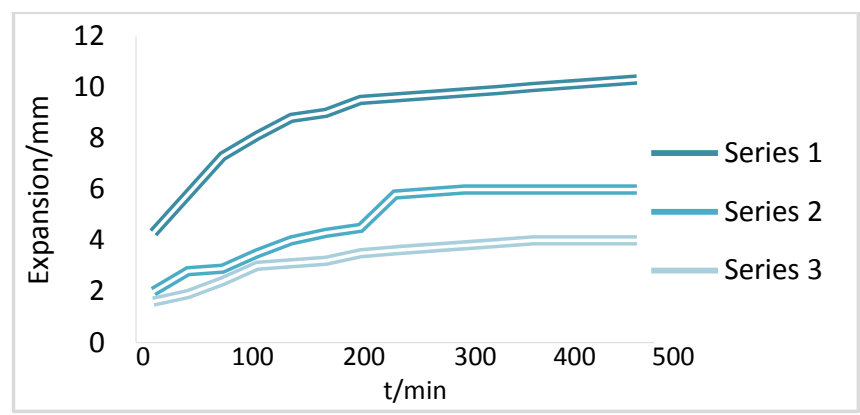

Figure 3. Core expansion in the drilling fluid.

It can be seen from Figure 3 that among the three solutions tested, the self-made drilling fluid has the smallest hydration swelling of the core, and the swelling volume does not change much with time. It can be seen that in terms of inhibiting hydration dispersion and cuttings expansion, the ability to self-distribute drilling fluid is very strong.

\subsection{Evaluation of Gas Layer Protection Effect}

According to SY5336-88 "Recommended Methods for Conventional Core Analysis" and SY/T5358-94 "Recommended Experimental Methods for Sandstone Reservoir Sensitivity Evaluation Experiments" [17] [18] [19]. It is known that the permeability recovery test of solid-free weak gel drilling fluid is the procedure and method to evaluate drilling fluid damage. Core tests in deep conventional tight gas reservoirs are carried out according to the recommended method. The core results of the experiments are shown in Table 5.

Table 5. Experimental results of permeability recovery value.

\begin{tabular}{rrrrr}
\hline Core & Well deep $/ \mathrm{m}$ & $K_{0} / 10^{-3} \mu \mathrm{m}^{2}$ & $K_{\mathrm{d}} / 10^{-3} \mu \mathrm{m}^{2}$ & $K_{\mathrm{d}} / K_{0} / \%$ \\
\hline $7^{\#}$ & 5080.32 & 3.72 & 3.31 & 88.9 \\
$8^{\#}$ & 5090.77 & 7.95 & 6.10 & 76.7 \\
$9^{\#}$ & 5101.13 & 9.12 & 7.88 & 86.4 \\
\hline
\end{tabular}

It can be seen from Table 5 that the drilling fluid has a good gas layer protection effect, and the permeability recovery value can reach $88.9 \%$, which meets the requirements of gas layer protection [17] [18] [19].

\subsection{Plugging Performance Evaluation}

This time, the plugging effect of the solid-phase weak gel drilling fluid was tested 
through the simulated fracture metal fracture plate of the high temperature and high pressure plugging instrument. The equipment is composed of a pressure control system, a simulated crack device and a kettle body device. The test was conducted under the experimental conditions of $150^{\circ} \mathrm{C}$ and $3.5 \mathrm{MPa}$. Then use the $\mathrm{FL}_{\mathrm{API}} / \mathrm{mL}$ and $\mathrm{FL}_{\mathrm{HTHP}} / \mathrm{mL}$ fluid loss testers were used to measure the changes in fluid loss over time in the room. Figure 4 shows the effect of the blocking layer formed during the experiment under the Zeiss stereo microscope. Table 6 shows the test results.

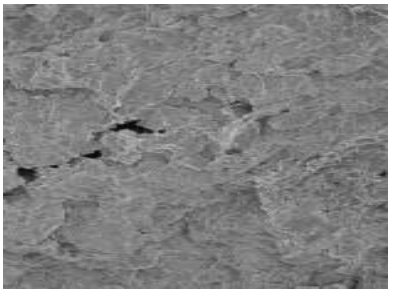

(a)

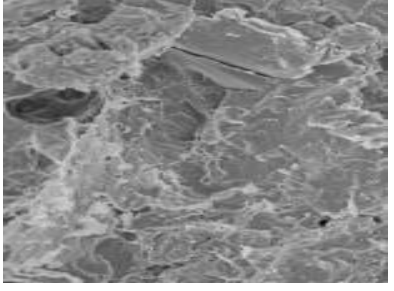

(b)

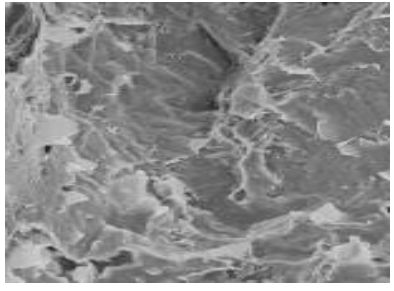

(c)

Note: (a), (b), and (c) are a new type of non-solid phase weak gel drilling fluid system $(\times 1000, \times 5000$, $\times 10.000$ times).

Figure 4. Blocking effect diagram of drilling fluid. (a) $50 \mu \mathrm{m}$; (b) $10 \mu \mathrm{m}$; (c) $5 \mu \mathrm{m}$.

According to the results shown in Figure 4, it can be seen that the plugging particles of WGL-1 with no solid phase weak gel tackifier become soft and deform under the required high temperature and pressure, and form a physical plugging layer in voids and cracks, and stabilize the well wall.

Table 6. Plugging performance test.

\begin{tabular}{rrr}
\hline$t / h$ & $\mathrm{FL}_{\mathrm{API}} / \mathrm{mL}$ & $\mathrm{FL}_{\mathrm{HTHP}} / \mathrm{mL}$ \\
\hline 0.5 & 2.4 & 2.7 \\
1.0 & 2.7 & 3.9 \\
2.0 & 3.7 & 5.2 \\
3.0 & 4.5 & 5.9 \\
4.0 & 5.6 & 6.5 \\
5.0 & 6.1 & 6.8 \\
6.0 & 6.5 & 7.4 \\
\hline
\end{tabular}

According to Table 6, $\mathrm{FL}_{\mathrm{API}} / \mathrm{mL}$ and $\mathrm{FL}_{\mathrm{HTHP}} / \mathrm{mL}$ are $6.5 \mathrm{ml}$ and $7.4 \mathrm{ml}$ respectively at $6 \mathrm{~h}$. According to the results of two experiments, it can be seen that its plugging performance is good.

\subsection{Static Settlement Stability Evaluation}

The larger the value of SSSI (Static Stable Stratification Index), then more serious the sedimentation of the drilling fluid would occur. Specific test steps: first the drilling fluid was placed in the aging tank, kept static at $150^{\circ} \mathrm{C}$ for a period of 15 days. Then, the drilling fluid was layered in the aging tank into four layers: 
free fluid layer, upper, middle and lower layer. Observing, recording and calculating the volume and density of each layer respectively, and obtain the value of the stratification index SSSI [20] [21] [22] was obtained. The results are shown in Table 7.

Table 7. SSSI evaluation result of drilling fluid at $150^{\circ} \mathrm{C}$.

\begin{tabular}{rrrrrrr}
\hline $\mathrm{t}_{\text {Static constant time }} / \mathrm{d}$ & $\begin{array}{r}\text { Dispensing } \\
\text { rate\% }\end{array}$ & & & $\rho /\left(\mathrm{g} \cdot \mathrm{cm}^{-3}\right)$ & SSSI \\
& 0 & 0 & 1.50 & 1.50 & 1.50 & 0 \\
\hline 1 & 1.1 & 1.49 & 1.51 & 1.54 & 0.016 \\
3 & 3.6 & 1.48 & 1.52 & 1.59 & 0.045 \\
7 & 6.0 & 1.47 & 1.54 & 1.63 & 0.072 \\
15 & 9.8 & 1.46 & 1.56 & 1.67 & 0.101 \\
\hline
\end{tabular}

The results in Table 7 refer to the relevant manuals [20] [21] [22]. The settling stability of the solid-phase weak gel drilling fluid system is good. The SSSI value increases with the increase of the standing time, and its stability changes. The time of deterioration of its stability occurred in the period of 1 to 3 days.

\section{Conclusions}

1) Preliminary discussion of the mechanism of action confirmed that WGL-1 has good gel forming properties, high temperature resistance, good high salt resistance, no toxicity, and good environmental friendliness, which can meet the requirements of drilling engineering for environmental protection.

2) The new formula studied is: water $+(0.3 \% \sim 0.5 \%) \mathrm{NaOH}+5 \% \mathrm{KCl}+2 \%$ WGL-1 $+5 \% \mathrm{NaCl}+(1.0 \% \sim 2.0 \%)$ HBFR Anti-high temperature fluid loss agent $+2 \%$ polyvalent polyol $+(1.5 \% \sim 2.0 \%)$ SDL-1 lubricant $+0.4 \%$ A $4 \mathrm{O} 1$. Tested its performance, this drilling fluid formula has good temperature resistance at $150^{\circ} \mathrm{C}$; the cuttings recovery rate is $96.78 \%$, and its suppression performance is good; the penetration recovery value is $88.9 \%$, and the gas formation protection performance is good; $\mathrm{FL}_{\mathrm{API}} / \mathrm{mL}$ and $\mathrm{FL}_{\mathrm{HTHP}} / \mathrm{mL}$ are $6.5 \mathrm{ml}$ and $7.4 \mathrm{ml}$ respectively at $6 \mathrm{~h}$, and the sealing performance is good under high temperature and high pressure, good settlement stability. This drilling fluid formula has achieved the expected effect and laid a foundation for further promoting the development of solid-free drilling fluid systems.

\section{Conflicts of Interest}

The authors declare no conflicts of interest regarding the publication of this paper.

\section{References}

[1] Sun, H.Y. and Liu, Y.Y. (2008) Drilling Fluid. Petroleum industry Press, Beijing, $1-150$. 
[2] Yan, J.N. (2001) Drilling Fluid Technology. China University of Petroleum Press, Dongying, 1-75.

[3] Wang, Z.H. (2001) Understanding of the Development of Drilling Fluid Additives and Drilling Fluid Systems in China. Drilling and Completion Fluids, 18, 32-35.

[4] Wei, Y., Cheng, F. and Zheng, H. (2008) Synthesis and Flocculating Properties of Cationic Starch Derivatives. Carbohydrate Polymers, 74, 673-679. https://doi.org/10.1016/j.carbpol.2008.04.026

[5] Pal, S., Mal, D. and Singh, R.P. (2005) Cationic Starch: An Effective Flocculating Agent. Carbohydrate Polymers, 59, 417-423. https://doi.org/10.1016/j.carbpol.2004.06.047

[6] Fanta, G.F. and Shogren, R.L. (1997) Modification of Starchpoly(methyl acrylate) Graft Copolymers by Steam Jet Cooking. Journal of Applied Polymer Science, 65, 1021-1029.

https://doi.org/10.1002/(SICI)1097-4628(19970801)65:5<1021::AID-APP20>3.0.CO $\underline{; 2-3}$

[7] Qiao, Y., Li, S., Wei, P.Z., et al. (2014) Study on the Modification of High Temperature Salt-Tolerant Starch Filtration Reducer. Drilling Fluid \& Completion Fluid, 31, 19-22.

[8] Wang, D.L., Wang, J.M., Song, Z.J., et al. (2010) Preparation and Properties of a Novelinor Ganicsilicon Modified Sodium Carboxyl Methylstarch Filtrate Reducer. Petrochemical Technology, 39, 440-443.

[9] Xiang, C.G. (2012) Research on Weak Gel Water-Based Drilling Fluid and Its Action Mechanism. Master's Thesis of Southwest Petroleum University, Chengdu.

[10] Jones, F.V. (1990) Alternate Environmental Testing of Drilling Fluids: An International Perspective. The European Petroleum Conference, The Hague, October 1990, SPE-20889-MS.

[11] Yi, S.J. and Yu, Y.H. (2002) Petroleum and Environmental Microbial Technology. China University of Geosciences Press, Beijing.

[12] Wan, L.P., Ji, X.X., Liu, Z.D., et al. (2020) Formulation of High Temperature Foaming Drilling Fluid and Performance Evaluation. Drilling Fluid \& Completion Fluid, 37, 71-76.

[13] Zhang, Q.G., Chen, F., Liu, Y., et al. (2007) Development Status of Foreign High-Performance Water-Based Drilling Fluids. Drilling Fluid \& Completion Fluid, 24, 74-78.

[14] Ding, T.W. and Yan, J.N. (2007) Laboratory Study on High Temperature and High Density Water-Based Drilling Fluid System. Journal of the University of Petroleum: Natural Science Edition, No. 2, 73-79.

[15] Zhong, H.Y., Qiu, Z.S., Huang, W.A., et al. (2010) Experimental Evaluation of the Characteristics of Polyamine Water-Based Drilling Fluids. Oilfield Chemistry, 27, 119-123.

[16] Zhong, H.Y., Huang, W.A., Lin, Y.X., et al. (2011) Performance Evaluation of a New Type of Polyamine Shale Inhibitor. Petroleum Drilling Technology, 39, 44-48.

[17] Ye, C., Rong, K.S., Xiang, D.M., et al. (2017) Development and Performance Evaluation of Shale Amine Inhibitor PEDAS. Fault Block Oil and Gas Field, 24, 269-272, 288.

[18] SY5336-88, Recommended Methods for Conventional Core Analysis.

[19] SY/T5358-94, Recommended Experimental Method for Sensitivity Evaluation Experiment of Sandstone Reservoir. 
[20] Zeng, W. and Bouguetta, M. (2016) A Comparative Assessment of Barite SAG Evaluation Methods. SPE Deepwater Drilling and Completions Conference, Galveston, September 2016, SPE-180348-MS. https://doi.org/10.2118/180348-MS

[21] Ye, Y., Yin, D., Liu, C.Q., et al. (2005) A Device and Method for Measuring Settlement Stability of High-Density Oil Test Working Fluid. CN102818881B.

[22] Parvizinia, A., Ahmed, R.M. and Osisanya, S.O. (2011) Experimental Study on the Phenomenon of Barite Sag. International Petroleum Technology Conference, Bangkok, November 2011, IPTC-14944-MS. https://doi.org/10.2523/IPTC-14944-MS 